\title{
Production of Biodiesel from Oleic Acid and Methanol by Reactive Distillation
}

\author{
Kusmiyati *, and Agung Sugiharto \\ Chemical Engineering Department, Faculty of Engineering, University Muhammadiyah \\ Surakarta, Jl. A. Yani Tromol Pos I Surakarta, Indonesia
}

Received: 1 January 2010, Revised: 18 March 2010; Accepted: 18 March 2010

\begin{abstract}
Biodiesel is an alternative diesel fuel that is produced from vegetable oils and animal fats. Generally, it is formed by transesterification reaction of triglycerides in the vegetable oil or animal fat with an alcohol. In this work, esterification reaction was carried out using oleic acid, methanol and sulphuric acid as a catalyst by reactive distillation method. In order to determine the best conditions for biodiesel production by reactive distillation, the experiments were carried out at different temperature $\left(100{ }^{\circ} \mathrm{C}, 120{ }^{\circ} \mathrm{C}, 150{ }^{\circ} \mathrm{C}\right.$ and $\left.180{ }^{\circ} \mathrm{C}\right)$ using methanol/oleic acid molar ratios (1:1, 5:1, 6:1, 7:1, 8:1), catalyst/ oleic acid molar ratios (0.5\%wt, $1 \% \mathrm{wt}, 1.5 \% \mathrm{wt}$ and $2 \% \mathrm{wt})$ and reaction times $(15,30,45,60,75$ and 90 minutes). Results at temperature $180{ }^{\circ} \mathrm{C}$, methanol/ oleic acid molar ratio of $8: 1$, amount of catalyst $1 \%$ for 90 minute reaction time gives the highest conversion of oleic acid above 0.9571 . Biodiesel product from oleic acid was analysed by ASTM (American Standard for Testing Material). The results show that the biodiesel produced has the quality required to be a diesel substitute. (C) 2010 BCREC UNDIP. All rights reserved.
\end{abstract}

Keywords: Biodiesel, reactive distillation, oleic acid, esterification

\section{Introduction}

Renewable energy has attracted more attention recently. Biodiesel, one of the renewable energy, has been recognized as an interesting fuel that substituted diesel oil produced from petroleum. The use of biodiesel has two advantages: it can reduce the dependency of petroleum oil which leads to an increase oil prices and it can reduce the environmental pollutants (Al-Widyan and AlSyoukh, 2002). Biodiesel is produced mostly from vegetable oil which is used edible oil such as palm oil, sunflower, soybean via transesetrification process using sodium hydroxide as a catalyst. However, the commercialization production of biodiesel from those vegetable oils still have drawback due to high cost of the vegetable oil and the purification of biodiesel product. Therefore, it is necessary to develop a process in order to produce biodiesel more efficient and economical. One approach for production of biodiesel has been conducted by using Jatropha oil instead of edible oil as feedstock. The Jatropa oil contains 20\% saturated fatty acids and 80\% unsaturated ones. The unsaturated fatty acid, oleic acid, is the most abundant (44.8\%) followed by linoleic acid (34\%), palmitic acid (12.8\%) and stearic acid (7.3\%) (Shah et al., 2004). One kind of fatty acid derived from the Jatropa oil, oleic acid, could be used as raw material to produce biodiesel by using esterification reaction using alcohol such as

\footnotetext{
* Corresponding Author.

E-mail: rahmadini2009@yahoo.com
} 
methanol, ethanol, etc. At present, the esterification of fatty acid and alcohol into fatty acid ester is usually conducted in a batch reactor (Omota et al., 2003). However production biodiesel from esterification reaction in the conventional batch reactor has many problems because of its low conversion, heavy capital investments and high energy costs so this process is not economically ( Gao et al., 2007) . To resolve the problems, it has been developed an advanced technology for biodiesel production. This method is known as a reactive distillation (RD) (Mattalana et al., 2009). The reactive distillation is a fascinating way for the biodiesel production due to the process able to reduce investments and energy costs (Lai et al., 2006).

Reactive distillation combines both separation and reaction in one unit and has been applied industrially for a number of years. Reactive distillation can offer significant economic advantages for certain cases, particularly for systems that involve reversible reactions. Examples of commercial successes of reactive distillation include nylon 6.6 processes, methyl acetate processes, ethyl acetate processes and methyl tert-butyl ether processes (Doherty \& Buzad, 1992). Another example of RD application includes esterification, ester hydrolysis, and ether synthesis (Mahajan et al., 2007; He et al., 2006, Harmsen, 2007; Po1pken et al., 2001; Kiss et al., 2006).

Reactive Distillation (RD) has many advantages, such as (Villgrana, et al., 2006):

1. Normally, excess of reactants is used to minimize side reactions and to overcome limitations imposed by chemical equilibrium. In reactive distillation, the continuous separation reduces the necessity for excess of reactants and it may be carried out close to stoichiometric feed conditions.

2. Reactive distillation can help the elimination of azeotrops in the mixture.

3. Reactive distillation can reduce the subsequent processing.

4. Reactive distillation can use the heat of reaction to heat the mixture and evaporate liquid and it may simplify the control of temperature.

5. Reactive distillation can increase conversion and improve selectivity of the product.

The aim of this work is the study of the production of biodiesel by esterification of oleic acid with methanol in a reactive distillation column. The esterification of oleic acid using sulfuric acid as a catalyst has been investigated at different process conditions: temperature, oleic acid : methanol ratio, sulfuric acid concentrations.

\section{Materials and Methods}

The reaction was carried out in a lab scale reactive distillation column that consists of a 500 $\mathrm{ml}$ flask equipped with warmer jacket to set up a constant reaction temperature, mechanical agitation, and packing column distillation. Oleic acid (99\%) and methanol (99\%) are used as raw material and sulfuric acid (98\%) is used as catalyst. These chemicals were obtained commercially from Sigma-Aldrich (USA). The feed is charge into the flask in the bottom of the rectifying column that also used as a reactor and reboiler. At the end of the separation the content in the column will drain down into the still and residual bottom fraction is the product. For temperatures above $100{ }^{\circ} \mathrm{C}\left(100{ }^{\circ} \mathrm{C}, 120^{\circ} \mathrm{C}, 150^{\circ} \mathrm{C}\right.$ and $180{ }^{\circ} \mathrm{C}$ ) was chosen as a representative temperatures to bringing back the methanol to major reactor of distillation. So,methanol can be used again as reuse material as organic compound in the process.

Esterification of fatty acid is a reversible reaction and water is formed. Removal of water can drive the reaction equilibrium to the completion and therefore increase the conversion. The best solution is working at temperatures above $100{ }^{\circ} \mathrm{C}$, in a system with continuos water removal. By removing water as by-product the equilibrium is shifted towards ester formation. The ester (biodiesel) will always be separated in the bottom of the reactive distillation column. Water is present as side product and typically is removed as top product due to its lower boiling point, together wit the alcohol if it is volatile (and not completely converted) or if it forms azotropes with water. A higher reflux ratio is not beneficial as it brings back water into the column, hence decreasing the conversion by shifting the equilibrium towards ester hydrolysis. Furthermore ASTM (American Standard for Testing Materials) was applied for analyzed the product. Variables studied for this experiment were: the effect of reaction time, the effect of reaction temperature, the effect of ratio alcohol to oleic acid, the effect of amount of catalyst in relation to the mount of refined oil.

\section{Results and Discussion}

\subsection{Effect of reaction time}

Effect of reaction time on the oleic acid conversion is shown in Figure 1. To achieve a well mixing between the reagents and the oleic acid 
during reaction, they must be stirred well at constant rate. The oleic acid conversion increased rapidly with the reaction time ranges between 15 min until $75 \mathrm{~min}$, after that, the conversion kept rising very slowly and then relatively constant at a value above 0.9389 for $75 \mathrm{~min}$. This mean that the reaction approved to be in equilibrium and the rate was quite slow. The production of methyl ester reached the maximum value at 0.9581 for 90 minute. Meng et al., (2008) studied the effect of reaction in production of biodiesel from Waste Cooking Oil (WCO) and methanol with sodium hydroxide catalyst under following conditions: temperature of $50{ }^{\circ} \mathrm{C}$, methanol/oil molar ratio of $6: 1$, weight catalyst of $1.0 \mathrm{wt} \% \mathrm{NaOH}$. The results showed that WCO conversion increased rapidly with the reaction time ranges between 30 min and $60 \mathrm{~min}$, after that, the conversion kept rising but very slowly and then practically constant above $86 \%$ at $90 \mathrm{~min}$.

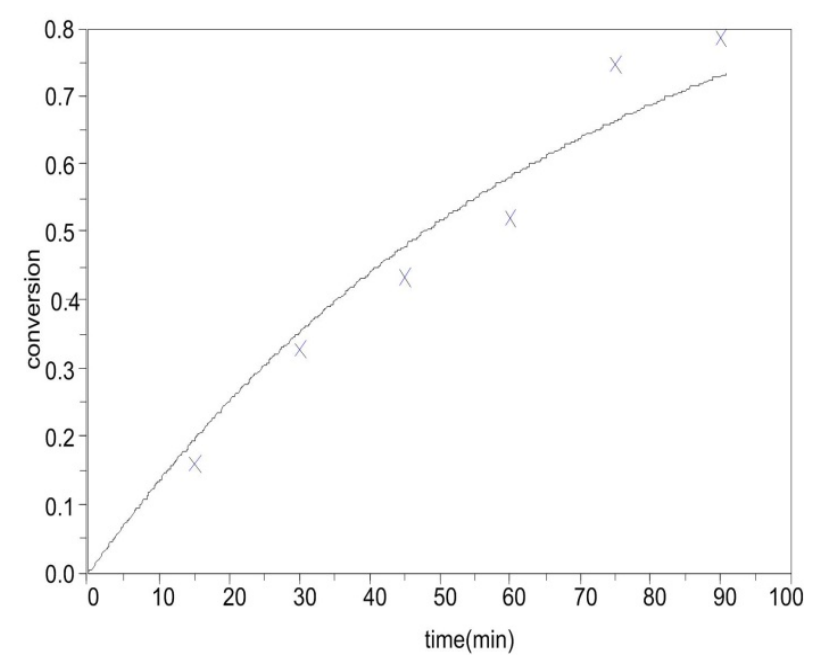

Figure 1. Effect of reaction time on methyl ester conversion. Reaction condition: ratio oleic acid: methanol $8: 1$, weight of the catalyst $1 \% \mathrm{wt}$ and temperature reaction $180^{\circ} \mathrm{C}$

\subsection{Effect of reaction temperature}

In this work, esterification reaction was studied using: ratio of oleic acid and methanol 8:1, weight of catalyst $1 \%$ wt $\mathrm{H}_{2} \mathrm{SO}_{4}$ (by weight of oleic acid), with four different temperatures (100 ${ }^{\circ} \mathrm{C}, 120{ }^{\circ} \mathrm{C}, 150{ }^{\circ} \mathrm{C}$ and $\left.180{ }^{\circ} \mathrm{C}\right)$. The results showed that the reaction was typically endothermic, when temperature increased, the final conversion increase as well as shown in figure 2 . The reaction rate at $150{ }^{\circ} \mathrm{C}$ was significantly faster than $120{ }^{\circ} \mathrm{C}$, but after $150{ }^{\circ} \mathrm{C}$ the increasing of conversion is not significant. The maximum conversion was reached at temperature $180{ }^{\circ} \mathrm{C}(0.9581)$. The transesterification reaction at different temperatures was also studied by Freedman et al., (1986). They studied the transesterification of refined soybean oil and methanol using ratio of methanol:oil $6: 1,1 \%$ $\mathrm{NaOH}$, at three different temperatures. The result showed that after 0.1 hour reaction time, ester yields were $94.87 \%, 72.85 \%$ and $64 \%$ at temperature $60{ }^{\circ} \mathrm{C}, 45{ }^{\circ} \mathrm{C}$ and $32{ }^{\circ} \mathrm{C}$, respectively. However after 1 hour of the reaction time, the formation of ester was identical at different temperatures 60 and $45{ }^{\circ} \mathrm{C}$ while at the temperature $32{ }^{\circ} \mathrm{C}$ the conversion was slightly lower.

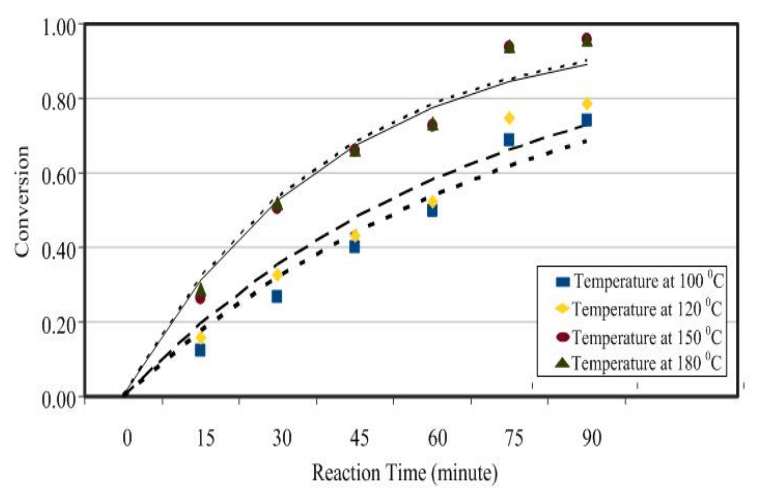

Figure 2. Effect of temperature in oleic acid conversion. The reaction condition ratio methanol oleic: acid $=8: 1,1 \%$ wt $\mathrm{H}_{2} \mathrm{SO}_{4}$ catalyst, reaction time 90 minute

\subsection{Effect of catalyst amount}

The amount of catalyst also plays a role on the conversion of the esterification reaction. The varying amount of catalysts was studied in this work at the following reaction condition: ratio methanol oleic: acid $=8: 1$, at constant temperature $130{ }^{\circ} \mathrm{C}$, during 90 minute of reaction time. The results are displayed in Figure 3 and shows that the reaction was highly dependent on the amount of catalyst. The most effect of catalyst amount was obviously seen for the catalyst amount below $1 \%$ weight. However the further added of catalyst amount above 1\%, it didn't give in increasing the conversion significantly. Canakci (2006) studied the transesterification reaction of waste cooking oil and methanol with acid catalyst. Three different catalyst amounts, $1 \%, 3 \%$ and $5 \%$ of sulfuric acid were used. For each case, the reaction conducted for 48 hours at 
$60{ }^{\circ} \mathrm{C}$ with a $6: 1$ molar ratio of methanol to oil. Ester formation increased with increasing catalyst amount. The ester conversions were $72.7 \%, 87.8 \%$ and $95.05 \%$ at $1 \%, 3 \%$ and $5 \%$ sulfuric acid respectively. Peng et al., (2008) studied the effect of catalyst concentration in three different conditions (1, 3 and 5 wt \%) for the synthesis of biodiesel from oleic acid and methanol. The reaction took place at $200 \circ \mathrm{C}$, and molar ratio of methanol to oil 9:1. The result showed that with increasing the catalyst concentration from 1 to $3 \% \mathrm{wt}$, the yield of methyl ester increased markedly from $84 \%$ to $92 \%$ reapectively. However, when the catalyst concentration was further increased to 5 wt \%, the reaction rate and methyl ester yield just slightly increased.

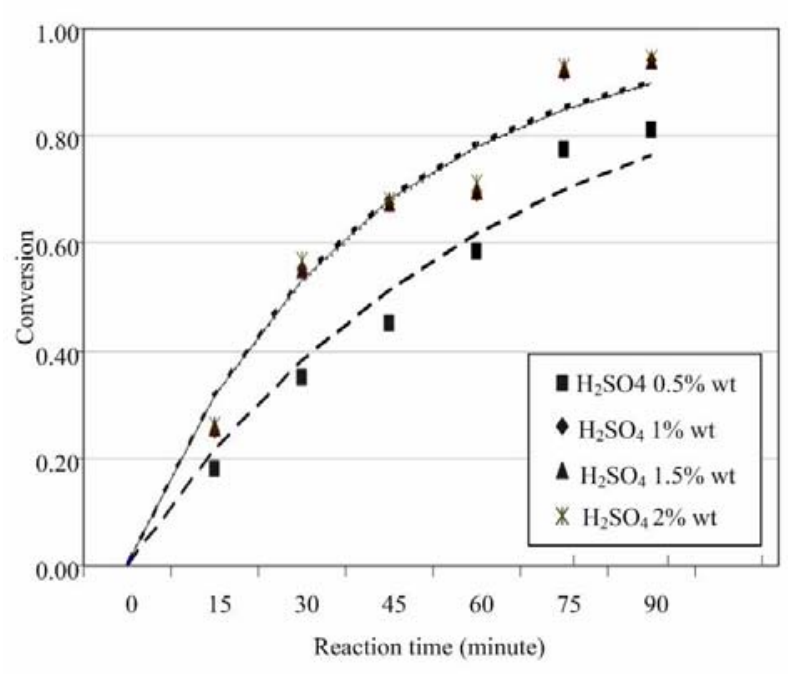

Figure 3. Effect of catalyst amount in oleic acid conversion. The reaction condition ratio methanol oleic: acid $=8: 1,1 \%$; temperature $130{ }^{\circ} \mathrm{C}$, reaction time 90 minute

\subsection{Effect of molar ratio}

The other important variable that is affecting the conversion of ester is molar ratio of alcohol to triglyceride. The stoichiometric ratio for transesterification reaction requires three mole of alcohol and one mole of triglyceride to yield three moles of fatty acid ester and one mole of glycerol. With the methanol/oil molar ratio increasing, oleic acid conversion will be correspondingly increased. In this work, biodiesel was produced from oleic acid and methanol at various molar ratios methanol/oleic acid (1:1, 5:1, 6:1, 7:1, 8:1) as shown in figure 4 . The figure shows that higher molar ratios result in greater ester conversion in a shorter time. The maximum conversion was achieved at 0.9571 using methanol/oleic acid molar ratio of $8: 1$, at temperature $150{ }^{\circ} \mathrm{C}$, catalyst weight $1 \%$ wt $\mathrm{H}_{2} \mathrm{SO}_{4}$ for 90 minute time of reaction. Wang et al., (2006) studied biodiesel formation using waste cooking oil and methanol as raw materials. The results showed that the conversion achieved was $91.6 \%$ for 3 hour when the molar ratio of methanol: oil was 3:1. Jacobson et al., (2008) produced biodiesel from waste cooking oil containing $15 \%$ free fatty acid and methanol using molar ratio methanol: oleic acid from 1:6 to $1: 18$. The yield of methyl esters increased from $81 \%$ to $98 \%$ after 10 hour reaction time was observed.

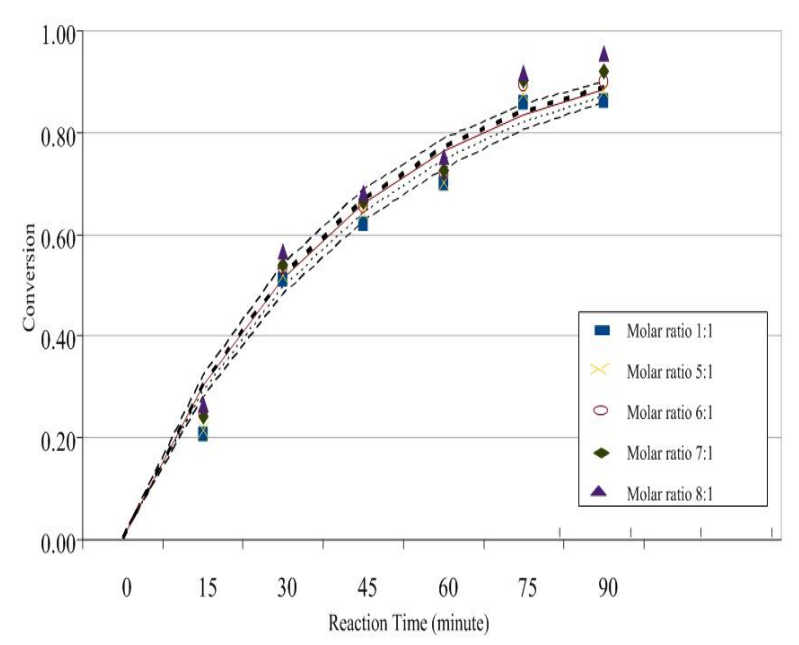

Figure 4. Effect of molar ratio methanol: oleic acid in oleic acid conversion. The reaction condition at $1 \%$ wt catalyst $\mathrm{H}_{2} \mathrm{SO}_{4}$, temperature $150{ }^{\circ} \mathrm{C}$, reaction time 90 minute

\subsection{Testing of Biodiesel obtained from oleic acid}

Biodiesel obtained from oleic acid was analyzed by ASTM (American Standard for Testing Material). Table 1 shows that biodiesel from this experiment is similar to petroleum diesel. As can be observed in table 1 the value of pour point, kinematic viscosity, flash point, specific gravity, and gross heating value are very similar to biodiesel from WCO and diesel oil from petroleum. The kinematics viscosity is important 
Table 1. Comparison of different biodiesel and diesel

\begin{tabular}{|c|c|c|c|c|}
\hline Fuel properties & This work & $\begin{array}{c}\text { Biodiesel from WCO } \\
(*)\end{array}$ & Diesel oil & Method of analyzed \\
\hline Pour Point, ${ }^{\circ} \mathrm{C}$ & -14 & -3.9 & -23 & ASTM D 97 \\
\hline $\begin{array}{c}\text { Kinematics Viscosity at } \\
40^{\circ} \mathrm{C} \mathrm{cSt}\end{array}$ & 4.537 & 4.8 & $1.9-6.0$ & ASTM D 445 \\
\hline Flash Point PM.C.C., ${ }^{\circ} \mathrm{C}$ & 172 & 177 & Min 120 & ASTM D 93 \\
\hline $\begin{array}{c}\text { Specific Gravity at } \\
60 / 60^{\circ} \mathrm{F}\end{array}$ & 0.8798 & 890 & $0.82 \mathrm{~s} / \mathrm{d} 0.89$ & ASTM D 1298 \\
\hline $\begin{array}{c}\text { Conradson Carbon Resi- } \\
\text { due, \%wt }\end{array}$ & 0.035 & - & - & ASTM D 189 \\
\hline $\begin{array}{c}\text { Gross Heating Value } \\
\mathrm{MJ} / \mathrm{kg}\end{array}$ & 43.8 & 39.8 & 45 & --.-.-.-. \\
\hline
\end{tabular}

$\left(^{*}\right)=$ Encinar et al., 2005

indicator the quality of fuel. High value of viscosity gives rise to poor fuel automization, incomplete combustion and carbon deposition on the injectors. Therefore, the biodiesel viscosity must below. As can be observed in table 1, the viscosity of 4.537 was obtained in this experiment. Heating value is important properties of biodiesel, the heating value measure the energy contained in the fuel. As can be observed in table 1 , the value $(43.8 \mathrm{MJ} / \mathrm{kg})$ is very similar with petroleum diesel oil (45 MJ/kg). The flash point is a measure of the tendency of a sample to form flammable mixture with air in controlled laboratory conditions. In this work the value is higher than those diesel oil $\left(120^{\circ} \mathrm{C}\right)$. This represents an advantage of biodiesel.

\section{Conclusions}

The biodiesel production from oleic acid has the quality required to be a diesel substitute. The result shows that variable-variable such as reaction time, \%wt $\mathrm{H}_{2} \mathrm{SO}_{4}$ catalyst, temperature reaction and molar ratio of methanol: oleic acid very influent for biodiesel production.

Maximum conversion above 0.9571 was reached at molar ratio methanol: oleic acid 8:1, $1 \%$ wt catalyst $\mathrm{H}_{2} \mathrm{SO}_{4}$, temperature reaction 180 ${ }^{\circ} \mathrm{C}$ and reaction time 90 minute.

The pour point, flash point, kinematics viscosity, specific gravity, gross heating value and conradson carbon residue are similar to those of diesel oil

\section{Acknowledgement}

The authors would like to thank the Ministry of Higher Education of Indonesia (DIKTI) for providing financial support under Fundamental Research program (contract no: 188/ SP2H/ PP/ DP2M/ III/ 2008).

\section{References}

[1] Al-Widyan, MI, and Al-Shyoukh, AO.(2002). Experimental Evaluation of the Transesterification of Waste Palm Oil Into Biodiesel, Bioresource Technology, 85, 253-256.

[2] Shah, Shweta., Sharma, Shweta and Gupta, M.N. (2004). Enegy and Fuel,18, 154-159.

[3] Omota, F., Dimian, A.C., and Bliek, A. (2003). Fatty Acid Esterification by Reactive Distillation: Part 2Kinetics-Based Design for Sulphated Zirconia Catalysts, Chemichal Engineering Science, 58, 3175-3176.

[4] Gao, J., Zhao, X. M., Zhou, L.V. and Huang, Z.H. (2007). Investigation of Ethyl Lactate Reactive Distillation Process, Institution of Chemichal Engineers, 85, 525-526.

[5] Mattalana, L.G., Gutierrez L.F., Cardona C.A., 2009, Biodiesel Production by reactive distillation, $1-9$.

[6] Lai, I.K., Hung, S.B., Yu, W.J., Le, M. and Huang, H.P.(2006). Design And Control Of Reactive Distillation For Ethyl And Isopropyl Acetates Production With Azeotropic Feeds, Chemichal Engineering. Science, 62, 878-898. 
[7] Doherty, M. F., and Buzad, G. (1992). Reactive Distillation by Design, Chemichal Engineering Research and Design, 70, 448-458.

[8] Mahajan, Yogesh S., Shah, Ankur K., Kamath, Ravindra S., Salve, Nankumar B., and Mahajani, Saljay M. (2007) Recovery of Trifluoroacetic from Dilute Aqueous Solution by Reactive Distilation, Separation Purification Technology xxx, 1-9.

[9] He, B.B., Singh, A.P., and Thomson, J.C. (2006). A Novel Continuous-Flow Reactor Using Reactive Distillation for Biodiesel Production, American Society of Agricultural and Biological Engineer, 49 (1), 107-112.

[10] Harmsen, G. Jan. (2007). Reactive Distillation : The Front-runner of Industrial Process Intensification A Full Review of Commercial Applications, Research, Scale-up, Design and Operation, Chemical Engineering and Processing, 46, 774-780.

[11] Polpken, T., Steinigeweg, S. and Gmehling, J. (2001). Synthesis And Hydrolysis Of Methyl Acetate By Reactive Distillation Using Structured Catalytic Packings: Experiments And Simulation, Ind. Eng. Chem. Res.,. 40, 1566-1574

[12] Kiss, A.A., Omota, F., Dimian, A.C. and Rothenberg, G. (2006)The Heterogeneous Advantage: Biodiesel by Catalytic Reactive Distillation, Topics in Catalyst, 40,141-151.
[13] Villgrana, A.D. Estrada, Sosa, G.B.Q., Alarc'on, M.L.J., V'azquez, L.O.A. and Dom'inguez, J.L. Cano.(2006). Comparison Between a Conventional Process And Reactive Distillation For Naphtha Hydrodesulfurization, Chemical Engineering and Processing, 45, 1036-1040.

[14] Meng, X., Chena, G. and Wang, Y. (2008).Biodiesel Production From Waste Cooking Oil Via Alkali Catalyst And Its Engine Test, Fuel. Process. Technol, 22, 313-320.

[15] Freedman, B., Pryde, E.H., and Butterfield, R.O. (1986). Transesterification Kinetics of Soybean Oil, JAOCS, 63, 1375-1380.

[16] Canacki, M. (2006). Production of Biodiesel from Feedstock With High Free Fatty Acids and Its effect on Diesel Engine Performance and emissions, Lowa State University. 77-81.

[17] Peng, B., Shu, Q., Wang, J., Wang, G., Wang, D. and Han, M. (2008). Biodiesel Production From Waste Oil Feedstock's By Solid Acid Catalysis, Process Safety and Environment Protection, 7, 21522.

[18] Wang, Y., Ou, s., Liu, P. and Zhang, Z. (2006). Preparation of Biodiesel From Waste Cooking Oil Via Two-Step Catalyzed Process, Energy Conversion and Management, 48, 184-188.

[19] Jacobson, K., Gopinath, R., Meher, L.C., and Dalai, A.K. (2008). Solid Acid Catalyzed Biodiesel 